Article

\title{
Analysis of Chemical Composition of Extractives by Acetone and the Chromatic Aberration of Teak (Tectona Grandis L.F.) from China
}

\author{
Hongyun Qiu ${ }^{1,2}$, Ru Liu ${ }^{2, *(\mathbb{D})}$ and Ling Long ${ }^{1,2, *}$ \\ 1 Research Institute of Forestry New Technology, Chinese Academy of Forestry, \\ Haidian 100091, Beijing, China; qiuqiuiuu@163.com \\ 2 Research Institute of Wood Industry, Chinese Academy of Forestry, Haidian 100091, Beijing, China \\ * Correspondence: liuru@criwi.org.cn (R.L.); longling@caf.ac.cn (L.L.); \\ Tel./Fax: +86-10-62889425 (R.L.); +86-10-62889475 (L.L.)
}

Received: 23 April 2019; Accepted: 21 May 2019; Published: 23 May 2019

\begin{abstract}
In order to clarify the chemical color change of teak (Tectona grandis L.F.), the difference of chemical composition between the heartwood and sapwood of teak was investigated by gas chromatography-mass spectrometry (GC-MS) based on the acetone extractive compounds. The results showed that the difference in content of the main components between heartwood and sapwood was not obvious. However, the amount of extractives in heartwood was higher than that in sapwood, especially for phenols, quinones, and ketones. The most obvious different substances in the acetone extractive between heartwood and sapwood were 4-tert-butyl-2-phenyl-phenol,2-methylanthraquinone, and 2,3-dimethyl-1,4,4a,9a-tetrahydro-9,10-anthracenedione, which might be the main composition for the chromatic aberration of teak. This paper focuses on a preliminary study and further work such as high-performance liquid chromatography (HPLC) with ultraviolet photometric detector (UV)/mass spectrometry (MS) will be carried out.
\end{abstract}

Keywords: acetone extractive; chemical composition; teak; chromatic aberration

\section{Introduction}

Teak (Tectona grandis L.F.), as one of the most famous timber species all over the world, is distributed from $73^{\circ} \mathrm{E}$ in India to $104^{\circ} 30^{\prime} \mathrm{E}$ in Thailand, and from the island of Java at $8^{\circ} 45^{\prime} \mathrm{S}$ to the low hills and plains which is below $800 \mathrm{~m}$ in northern Myanmar in terms of its origin [1]. It is widely used in boat masts and decks, furniture, railway sleepers and other applications due to its important advantages such as high hardness and durability, fine texture, beautiful texture, antiseismic performance, small shrinkage, etc. [2]. However, poor visual appearance in green teak is common by reason of the uneven and unstable surface color [3]. To provide basic information for the wood industry, the physical and mechanical properties and compositions of teak have been analyzed by many researchers [4-7]. A lot of research has been done into the breeding, plantations and growth of teak so as to develop high productivity and quality varieties [8]. Abundant genetic variation in photosynthetic traits and growth among the teak clones, relations between trace element in cultivated soil or bent sections and properties were obtained $[9,10]$, for instance. However, the chemical compositions were rarely reported. As the chemical composition of wood is one of the most important factors for its properties, it should not be ignored.

Extractives were used to identify different substance in wood [11], drug [12], food [13] and the like, although they account for small parts of the wood, and gives the wood its unique properties [14-16]. The reason why teak is loved by consumers is inseparable from its attractive appearance, and the unique color, which is highly correlative with the extractives. At present, the research on the chemical composition of teak is mostly around lignin, cellulose, and hemicelluloses [17]. Few studies are related 
to wood extractives, let alone to the extractives of teak in China [3,18-21]. Therefore, the analysis of the chemical composition of teak, especially its extractives, can provide a theoretical basis for the rules of the color change and color matching technology of teak, which has great research value in its practical application. The chemical constituents of teak from Yunnan province in China were researched quantitatively in this study. Acetone was used to extract the heartwood and sapwood of teak. The extractives were respectively analyzed by gas chromatography-mass spectrometry (GC-MS) to find the difference in composition between the two parts.

\section{Materials and Methods}

\subsection{Materials}

Eighteen-year-old teak was taken from Yingjiang, Dehong, Yunnan province, China. A disc with a diameter of about $20 \mathrm{~cm}$ in $5 \mathrm{~cm}$ thickness was taken from a $100 \mathrm{~cm}$-long teak log. Six logs were chosen in total, and the dics were selected from different position of the logs, namely, the top, middle, and bottom. They were exposed naturally for air-dried. The experiment reagents used in this study are listed in Table 1.

Table 1. Experiment reagent.

\begin{tabular}{|c|c|}
\hline Experiment Reagent & Manufacturers \\
\hline Distilled water & Guangzhou Watson's Food and Beverage Co., Ltd., Guangzhou, China \\
\hline Sodium hydroxide (analytical grade) & Beijing Chemical Plant, Beijing, China \\
\hline Sulfuric acid (analytical grade) & Beijing Chemical Plant, Beijing, China \\
\hline Benzene & Tianjin Fuchen Chemical Reagent Factory, Tianjin, China \\
\hline $\begin{array}{c}\text { Methanol (HPLC(high-performance liquid } \\
\text { chromatography) grade) }\end{array}$ & Mreda Technology Inc, California, USA \\
\hline Acetone (HPLC grade) & Duksan Pure Chemicals Co. Ltd., Ansansi Gyunggido, Korea \\
\hline
\end{tabular}

\subsection{Determination of Chemical Composition}

The relative Chinese standards were found based on the book of Shi and HE [22]; $5 \times 5 \times 50 \mathrm{~mm}^{3}$ sections of wood were chopped along the vertical direction of 6 teak discs. The sapwood and heartwood were ground by a pulverizer (1HP desktop high-speed pulverizer RT-34 from Rong Tsong Precision Technology Co., Taiwan, China) into mixture powder from 6 discs with 40-60 mesh respectively. The moisture of sapwood and heartwood of teak were determined by reference of GB/T 2677.2-1993 "Fibrous raw material-Determination of moisture content".

Determination of $\alpha$-cellulose and hemicellulose content were measured by reference of GB/T 744-1989 "Pulps-Determination of $\alpha$-cellulose" and GB/T 2677.10-1995 "Fibrous raw materialDetermination of holocellulose", respectively.

The determination of lignin was carried out in accordance with GB/T 2677.8-1994 "Fibrous raw material-Determination of acid-insoluble lignin".

The $\mathrm{pH}$ value was measured referring to GB/T 6043-1999 "Method for determination of $\mathrm{pH}$ of wood". $3 \mathrm{~g}$ wood flour sample was extracted by alcohol-benzene, $1 \% \mathrm{NaOH}$, cold water, hot water, and the acetone, respectively referring to GB/T 10741-1989 "Pulps-Determination of alcohol-benzene soluble", GB/T 2677.5-1993 "Fibrous raw material Determination of 1\% sodium hydroxide solubility", GB/T 2677.4-1993 "Fibrous raw material-Determination of water solubility" and GB/T 2677.6-1994 "Fibrous raw material-Determination of solvent extractives". After the extraction complete, the extractives were transferred to $50 \mathrm{ml}$ volumetric flasks and bring to volume.

\subsection{Total Phenol Content}

The total phenol content was measured with the cold water extractives and hot water extractives by spectrophotometry. The standard solution of gallic acid was detected by wavelengths at $780 \mathrm{~nm}$. Regression analysis of the data to obtain the regression equation is: $y=0.00059+0.1149 x$ ( $y$ is absorbance, $x$ is the total phenol content in the solution). 


\subsection{GC-MS Analysis}

The analysis was carried out by Fisher TSQ Quantum GC (gas chromatography) (Thermo Fisher, Massachusetts, USA). The chromatographic conditions were Agilent (Agilent Technologies Inc., California, USA) DB-1MS $(60 \mathrm{~m} \times 0.25 \mathrm{~mm} \times 0.25 \mu \mathrm{m})$ with column flow rate of $1.0 \mathrm{ml} / \mathrm{min}$. The inlet temperature was $250^{\circ} \mathrm{C}$, and split ratio was set at $15: 1$. The initial temperature was $40^{\circ} \mathrm{C}$ and rose to $280^{\circ} \mathrm{C}$ at $10^{\circ} \mathrm{C} / \mathrm{min}$, then retained for $15 \mathrm{~min}$. The mass spectrometry conditions were an EI (Electronic ionization) ionization source with electron bombardment energy of $70 \mathrm{eV}$, ion source temperature of $250{ }^{\circ} \mathrm{C}$, filament current of $100 \mu \mathrm{A}$, and transmission line temperature of $250^{\circ} \mathrm{C}$. The compounds were identified by comparing the MS (mass spectrometry) spectra to the National Institute of Standards and Technology (NIST) library (http://webbook.nist.gov/chemistry/, Maryland, USA) with retention time and indices.

\section{Results and Discussion}

\subsection{Components Analysis in Sapwood and Heartwood of Teak}

Lignin and extractives in wood are the main reasons for the different colors of wood. The main component contents and $\mathrm{pH}$ value of heartwood and sapwood of teak are shown in Table 2.

Table 2. Chemical components of woods.

\begin{tabular}{cccccc}
\hline & Moisture (\%) & $\begin{array}{c}\text { Acid-Insoluble } \\
\text { Lignin (\%) }\end{array}$ & $\begin{array}{c}\text { Holocellulose } \\
\mathbf{( \% )}\end{array}$ & $\begin{array}{c}\boldsymbol{\alpha} \text {-Cellulose } \\
\mathbf{( \% )}\end{array}$ & pH Value \\
\hline Heartwood & 3.90 & 26.76 & 58.27 & 34.97 & 5.79 \\
Sapwood & 4.25 & 27.73 & 62.23 & 35.53 & 5.84 \\
\hline
\end{tabular}

It can be found that the main component contents of teak between heartwood and sapwood were not significant. Both of them were in the weak acidic range. The moisture of heartwood was slightly lower than that of the sapwood. In addition to the structural difference of lignin, the extractives had a certain effect on the color of the teak wood. To obtain natural extracts, methods using solvents are the most common, in particular for herbs solid-liquid extraction, with the simplest being maceration [23]. As we know, the extractives extracted by different solvents from wood are different in type and content [24]. The water-soluble substances in wood are tannins, pigments, carbohydrates, plant alkaloid, cyclitol and some inorganic salts, while hot $1 \%$ sodium hydroxide solution can dissolve not only the water extractives, part of lignin, pentosan, hexosan and resin acids in wood, but also the furfural acid and the degraded components caused by light, heat, oxidation and bacteria. The alcohol-benzene solution not only has the ability of benzene to dissolve fats and waxes, but also has an excellent solubility to dissolve water in any proportion. So it can dissolve resins, fats and waxes, and also tannins, pigments, etc. Acetone extractives are mainly composed of fats, waxes, fatty acids, terpenoids, phenolic compounds, etc. [25-28]. The contents of the following extractives in sapwood and heartwood of teak are shown in Table 3.

Table 3. Contents of partial extractives in heartwood and sapwood of teak.

\begin{tabular}{|c|c|c|c|c|c|c|c|}
\hline & \multirow{2}{*}{$\begin{array}{c}\text { Hot Water } \\
(\%)\end{array}$} & \multirow{2}{*}{$\begin{array}{c}\text { Cold Water } \\
(\%)\end{array}$} & \multirow{2}{*}{$\begin{array}{c}\text { 1\% } \mathrm{NaOH} \\
(\%)\end{array}$} & \multirow{2}{*}{$\begin{array}{c}\text { Alcohol-benzene } \\
(\%)\end{array}$} & \multirow{2}{*}{$\begin{array}{c}\text { Acetone } \\
(\%)\end{array}$} & \multicolumn{2}{|c|}{ Total Phenol (\%) } \\
\hline & & & & & & Hot Water & Cold Water \\
\hline Heartwood & 10.22 & 6.40 & 22.34 & 14.54 & 10.13 & 1.35 & 0.71 \\
\hline Sapwood & 9.36 & 6.07 & 24.06 & 4.67 & 2.37 & 0.93 & 0.33 \\
\hline
\end{tabular}

As expected, the content of extractives (Table 3) in hot water was more than that in cold water, and the same phenomenon occurred in the total phenol. The total phenol, which exhibited good biological activities, was detected more in heartwood than sapwood. Obviously, the content in alcohol-benzene and acetone extractives between heartwood and sapwood was quite different. The 
chemical compositions extracted from alcohol-benzene were higher than others. Deng [29] obtained that the acetone can serve as an alternative for alcohol-benzene. Therefore, the acetone extractives in heartwood and sapwood of teak were analyzed by the gas chromatography-mass spectrometry (GC-MS), which can better identify the chemicals. By comparing the distinctions between the two parts, the reason why the color between heartwood and sapwood of teak could be understood.

\subsection{GC-MS Analysis of Acetone Extractives}

As the typical substance of teak, 2-methyl-anthraquinone was suspected to be the reason for the special color and surface properties of teak. According to the external standard method, the area of the standard solution at different concentration was detected by GC-MS. The standard curve drawn according to the test results is shown in Figure 1. Regression analysis of the data to obtain the regression curve of the standard curve was: $y=1.1991 \times 107 \times x$ ( $y$ is the peak area, $x$ is the content of 2-methyl-anthraquinone) with R2 of 0.9987. It can be seen from Figure 1 that the standard curve was approximately a straight line, which meant that the amount of the standard solution had a good linear relationship with the peak area.

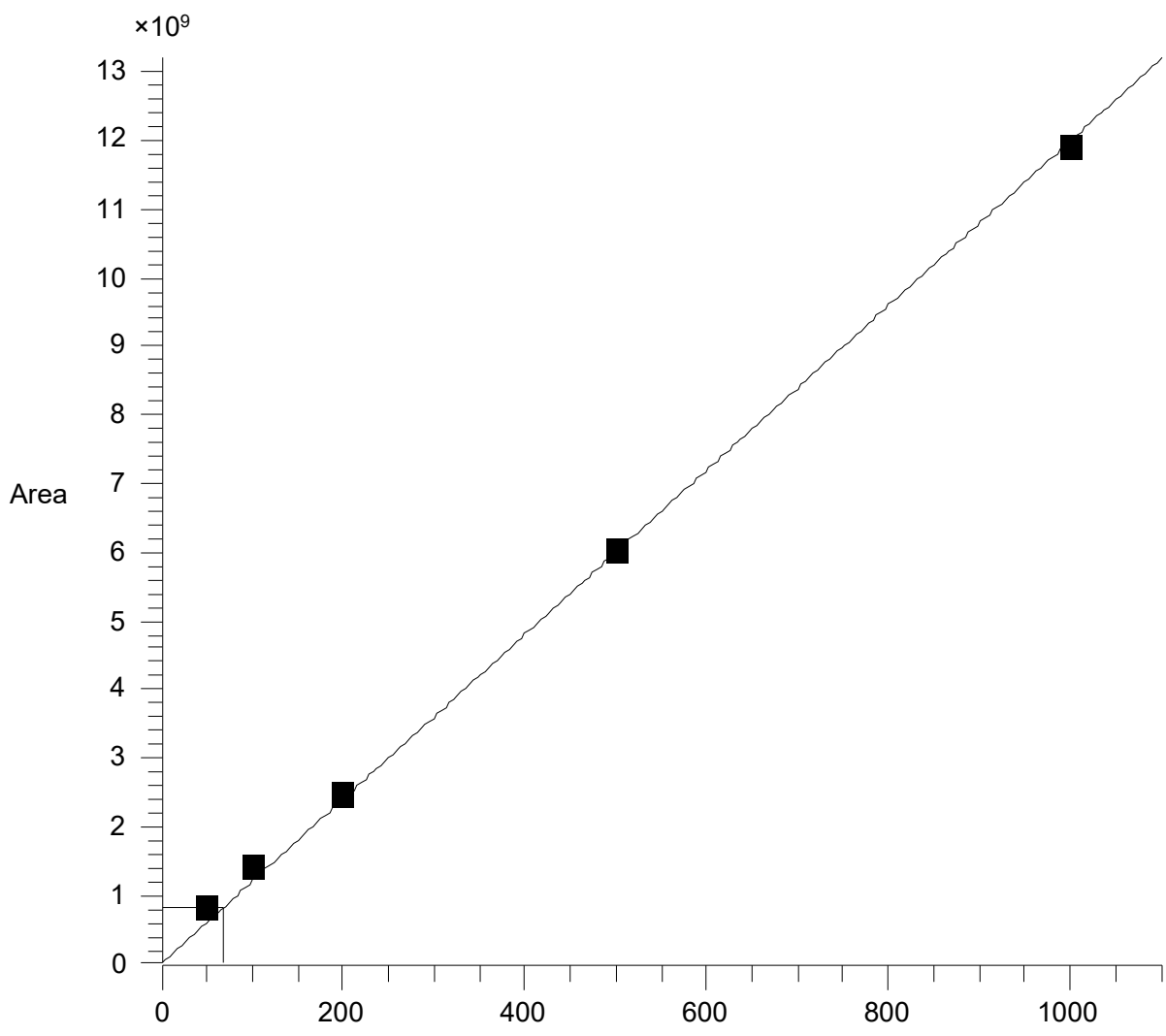

Figure 1. Standard curve about 2-methyl-anthraquinone and peak area.

The quantitative analysis of the other substance in the acetone extractive detected by GC-MS depended on the relationship of the peak areas between them and the 2-methyl-anthraquinone. The results of GC-MS analysis of acetone extracts in heartwood and sapwood of teak are shown in Figure 2 and Table 4, and the most prominent compositions are marked in Figure 2 in addition.

The acetone extractives in heartwood were higher in composition and content than those in sapwood (Figure 2). A total of 49 components (Table 4) were detected in the acetone extractives of the heartwood, including 10 kinds of alkanes, 2 kinds of olefins, 1 benzene series, 1 alcohol, 4 kinds of aldehydes, 8 kinds of ketones, 2 kinds of acids, 3 kinds of easters, 1 anhydride, 3 kinds of phenols, 7 kinds of hydrazines and 7 kinds of heterocyclics; while 26 kinds of components were detected in the acetone extractives of the sapwood, including 7 kinds of alkanes, 2 kinds of olefins, 1 alcohol, 1 
aldehyde, 4 kinds of ketones, 1 acid, 1 ester, 2 kinds of phenols, 5 kinds of hydrazines and 2 kinds of heterocyclics. The benzene series and acid anhydrides were not detected in the sapwood. Except for acetonyldimethylcarbinol and estriol, the rest components in sapwood were less than that in the heartwood. Although some extractives in the heartwood were undetected, most of the constituents with higher content can be detected in the sapwood.

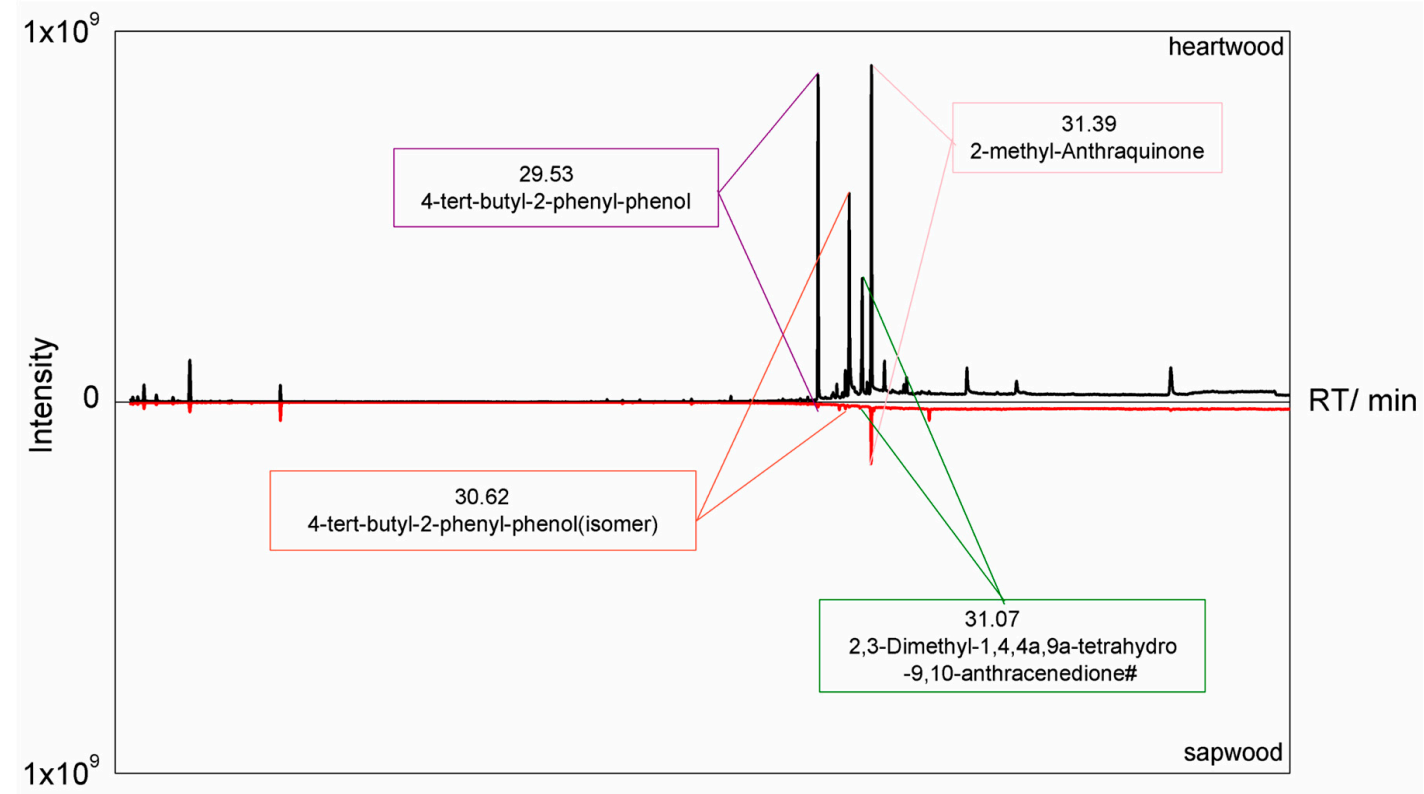

Figure 2. Gas chromatography-mass spectrometry (GC-MS) chromatogram of acetone extractive in the heartwood and sapwood of teak.

The components in acetone extractives of heartwood and sapwood are accumulated according to the type and shown in Table 5. The percentages of the various contents in heartwood and sapwood are shown in Figure 3.

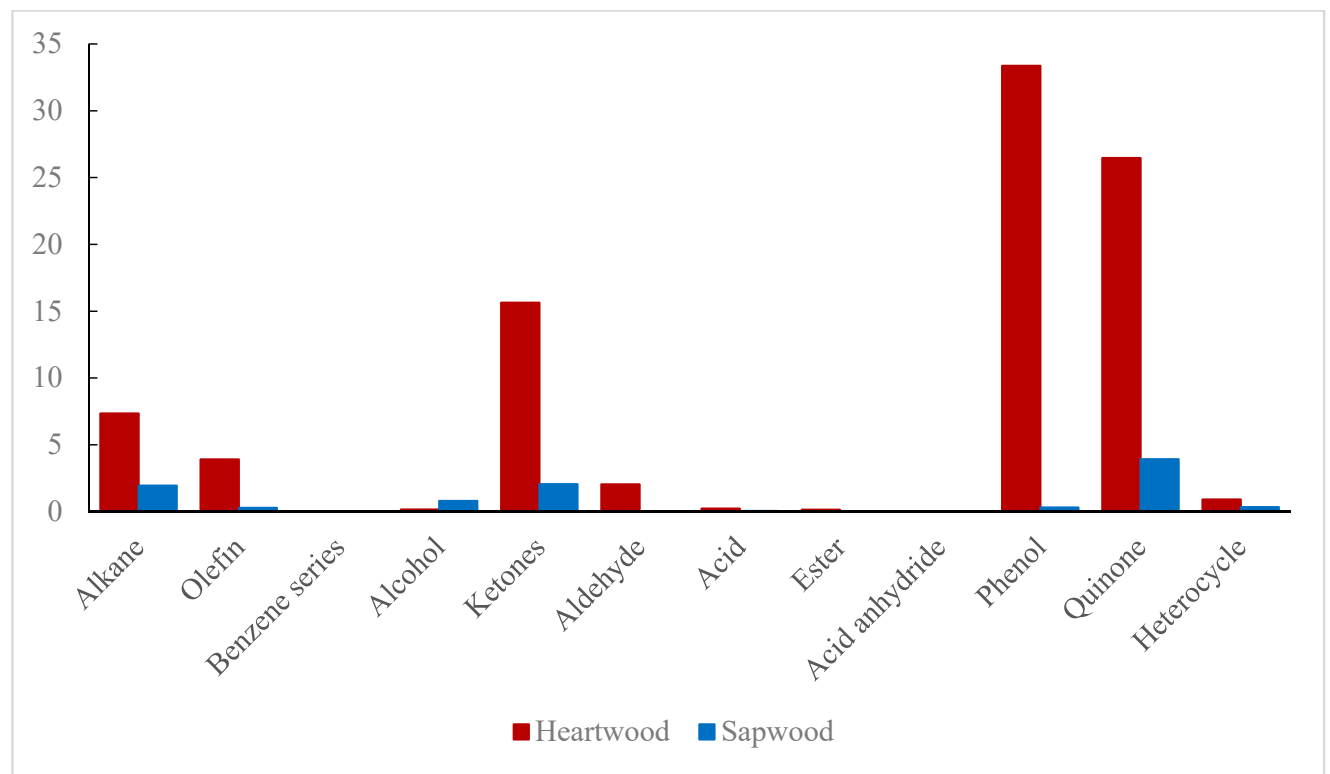

Figure 3. Contents of various compounds in acetone extractives in the heartwood and sapwood of teak. 
Table 4. GC-MS analytical results of acetone extractive compounds in heartwood and sapwood of teak.

\begin{tabular}{|c|c|c|c|c|c|c|}
\hline \multirow{2}{*}{ NO. } & \multirow{2}{*}{ Categories } & \multirow{2}{*}{$\begin{array}{l}\text { Retention } \\
\text { Time (min) }\end{array}$} & \multirow{2}{*}{$\begin{array}{l}\text { Retention } \\
\text { Index }\end{array}$} & \multirow{2}{*}{ Component } & \multicolumn{2}{|c|}{ GC Content $(\mu \mathrm{g} / \mathrm{g})$} \\
\hline & & & & & Heartwood & Sapwood \\
\hline 1 & \multirow{10}{*}{ Alkane } & 5.61 & 570 & 2-methyl-pentane & 45.01 & 13.89 \\
\hline 2 & & 5.79 & 584 & 3-methyl-pentane & 56.94 & 17.89 \\
\hline 3 & & 6 & 601 & N-hexane & 207.26 & 73.03 \\
\hline 4 & & 6.44 & 630 & Methyl-cyclopentane & 88.56 & 27.99 \\
\hline 5 & & 7.02 & 664 & Cyclohexane & 65.32 & 19.78 \\
\hline 6 & & 7.61 & 691 & Isooctane & 589.54 & 129.64 \\
\hline 7 & & 8.65 & 736 & 2,2,3-trimethylpentane & 7.54 & / \\
\hline 8 & & 9.06 & 630 & 2,3,4-trimethylpentane & 11.72 & 4.00 \\
\hline 9 & & 28.38 & 1360 & 5,8-diethyldodecane & 4.82 & / \\
\hline 10 & & 28.53 & 1387 & 9-n-hexylheptadecane & 5.02 & / \\
\hline 11 & \multirow{2}{*}{ Olefin } & 8.99 & 750 & 2,3-dimethyl-1-hexene & 5.65 & 4.21 \\
\hline 12 & & 41.85 & 2835 & All-trans-squalene & 569.65 & 36.83 \\
\hline 13 & $\begin{array}{l}\text { Benzene } \\
\text { series }\end{array}$ & 28.16 & 1323 & 1,3,5-triisopropyl-benzene & 4.61 & / \\
\hline 14 & Alcohol & 33.41 & 2970 & Estriol & 23.66 & 118.49 \\
\hline 15 & \multirow{8}{*}{ Ketones } & 10.77 & 811 & Acetonyldimethylcarbinol & 163.09 & 182.46 \\
\hline 16 & & 29.7 & 1927 & $\begin{array}{l}\text { 6-(1-Hydroxymethylvinyl)-4,8a-dimethyl- } \\
\text { 3,5,6,7,8,8a-hexahydro-1H-naohthalen-2-one }\end{array}$ & 13.40 & 2.53 \\
\hline 17 & & 30.19 & 1941 & $\begin{array}{l}\text { 2-Acetyl-3-methyl-3-phenyl-2,3-dihudro- } \\
\text { 5H-indazol-5-one }\end{array}$ & 145.50 & I \\
\hline 18 & & 31.07 & 1966 & $\begin{array}{l}\text { 2,3-Dimethyl-1,4,4a,9a-tetrahydro- } \\
\text { 9,10-anthracenedione }\end{array}$ & 1228.70 & 30.31 \\
\hline 19 & & 31.25 & 1971 & $\begin{array}{c}\text { Tetracyclo }[10 \cdot 2 \cdot 1 \cdot 0(2,11) \cdot 0(4,9)] \\
\text { petadeca-2(11),6,13-triene-5,8-dione }\end{array}$ & 107.40 & / \\
\hline 20 & & 31.85 & 1988 & 2-(3-Hydroxyphenyl)-1H-indene-1,3(2H)-dione & 320.73 & 4.42 \\
\hline 21 & & 32.14 & 1966 & $\begin{array}{l}\text { 2-Acetyl-3-methyl-3-phenyl-2,3-dihydro- } \\
\text { 5H-indazol-5-one }\end{array}$ & 58.41 & / \\
\hline 22 & & 36.46 & 3387 & 2-(2-Nitro-1-phenyl-2-propenyl)cyclohexanone & 266.51 & l \\
\hline 23 & \multirow{4}{*}{ Aldehyde } & 22.17 & 1285 & $\begin{array}{l}\text { 1,3-benzodioxole-5-carboxaldehyde } \\
\text { (Piperonal) }\end{array}$ & 20.94 & / \\
\hline 24 & & 26.49 & 1640 & (2E)-3-(1,3-benzodioxol-5-yl)-2-propenal & 47.10 & / \\
\hline 25 & & 32.62 & 2679 & $\begin{array}{l}\text { 9,10-dioxo-9,10-dihydro- } \\
\text { 1-anthracenecarbaldehyde }\end{array}$ & 170.20 & 4.21 \\
\hline 26 & & 33.15 & 2846 & $\begin{array}{l}\text { 1-methyl-1,2,3,4,4a,9,10,10a-octahydro- } \\
\text { 1-phenanthrenecarbaldehyde }\end{array}$ & 62.81 & / \\
\hline 27 & \multirow{2}{*}{ Acid } & 7.2 & 702 & Propanoic acid & 9.63 & l \\
\hline 28 & & 29.17 & 1912 & $\begin{array}{l}\text { 1,4-Dihydroxy-3-(3-methyl-2-butenyl)- } \\
\text { 2-naphthoic acid }\end{array}$ & 23.66 & 7.16 \\
\hline 29 & \multirow{3}{*}{ Ester } & 8.33 & 726 & Methyl isocyanate & 11.72 & / \\
\hline 30 & & 12.7 & 878 & Acrylic acid butyl ester & 3.35 & / \\
\hline 31 & & 28.77 & 1901 & Butyl(2-chlorocyclohexyl) methyl phthalate & 4.82 & 2.95 \\
\hline 32 & $\begin{array}{c}\text { acid } \\
\text { anhydride }\end{array}$ & 21.61 & 1322 & $\begin{array}{l}\text { 1,3-isobenzofurandione } \\
\text { (Phthalic anhydride) }\end{array}$ & 3.35 & l \\
\hline 33 & \multirow{3}{*}{ Phenol } & 27.31 & 1675 & 4-((1E)-3-hydroxy-1-propenyl)-2-methoxyphenol & 7.33 & / \\
\hline 34 & & 29.53 & 1922 & 4-tert-butyl-2-phenyl-phenol & 2675.75 & 23.99 \\
\hline 35 & & 30.62 & 1953 & 4-tert-butyl-2-phenyl-phenol (isomer) & 2230.46 & 21.68 \\
\hline 36 & \multirow{7}{*}{ Quinone } & 23.31 & 1427 & 1,4-naphthoquinone & 20.73 & / \\
\hline 37 & & 24.84 & 1469 & Menadione & 15.28 & / \\
\hline 38 & & 30.05 & 1937 & Anthraquinone & 101.54 & 2.10 \\
\hline 39 & & 30.48 & 1949 & $\begin{array}{c}\text { 2-hydroxy-3-(3-methyl- } \\
\text { 2-butenyl)-1,4-Naphthoquinone } \\
\text { (Lapachol) }\end{array}$ & 227.36 & 31.36 \\
\hline 40 & & 31.39 & 1975 & 2-methyl-anthraquinone & 3019.30 & 516.46 \\
\hline 41 & & 32.53 & 2855 & 1-Hydroxy-4-methylanthra- 9,10-quinone & 94.21 & 14.73 \\
\hline 42 & & 34.73 & 3064 & 2-(Hydroxymethyl)anthraquinone & 419.96 & 13.05 \\
\hline 43 & \multirow{7}{*}{ Heterocycle } & 26.09 & 1603 & 3,4-methylenedioxybenzhydrazide & 3.56 & / \\
\hline 44 & & 26.27 & 1612 & Dibenzo-p-dioxin & 4.61 & / \\
\hline 45 & & 28.3 & 1844 & $\begin{array}{l}\text { 5-methoxy-7-phenyl-bicyclo [3.2.0] } \\
\text { hept-2-en-6-one, (Z, exo+ endo) }\end{array}$ & 14.86 & / \\
\hline 46 & & 28.61 & 1876 & 1,2-benzisothiazol-3-amine tbdms & 6.70 & / \\
\hline 47 & & 28.92 & 1905 & 2-Hydroxydibenzofuran & 26.59 & 4.00 \\
\hline 48 & & 30.28 & 1944 & $\begin{array}{l}\text { 4a-methyl-1-methylene- } \\
1,2,3,4,4 a, 9,10,10 a-o c t a h y d r o p h e n a n t h r e n e\end{array}$ & 50.87 & 45.25 \\
\hline 49 & & 35.79 & 3241 & Lochnerine & 26.80 & / \\
\hline
\end{tabular}


Table 5. The content of acetone extractive in heartwood and sapwood of teak (by category).

\begin{tabular}{ccc}
\hline & Heartwood $(\mu \mathrm{g} / \mathrm{g})$ & Sapwood $(\mu \mathrm{g} / \mathrm{g})$ \\
\hline Alkane & 1081.73 & 286.22 \\
Olefin & 575.30 & 41.04 \\
Benzene series & 4.61 & 0.00 \\
Alcohol & 23.66 & 118.49 \\
Ketones & 2303.73 & 301.79 \\
Aldehyde & 301.05 & 4.21 \\
Acid & 33.29 & 7.16 \\
Ester & 19.89 & 2.95 \\
Acid anhydride & 3.35 & 0.00 \\
Phenol & 4913.54 & 45.67 \\
Quinone & 3898.38 & 577.70 \\
Heterocycle & 133.99 & 49.25 \\
\hline
\end{tabular}

Alkanes, ketones, phenols and quinones (Table 5 and Figure 3 ) in acetone extractives had relatively high contents in heartwood, while in sapwood, the ketones, phenols and quinones were much less. The content of benzene, alcohols, acids, esters, acid anhydrides and heterocyclics were very low both in the heartwood and sapwood, while the substances of olefins, aldehydes and phenols accounted for a certain proportion in the heartwood but were hardly present in the sapwood. In particular, the phenols, which had the highest content in the heartwood, was rarely found in the sapwood. Among the above content, the most prominent chemical compositions are shown in Table 6.

Table 6. The compounds in the heartwood and sapwood of teak with obvious difference in content.

2,3-Dimethyl-1,4,4a,9a-tetrahydro-

Components like lappaol, deoxylactam and its isomers, such as squalene, chloranol, palmitic acid, etc. were all detected in teak indigenous to Java Island, Yogyakarta and Panama. Similar substances were found in this research. Due to the different origins, the content of each component was different. The tectol with higher content detected in teak from Indonesia, did not appear in this experimental result; 4-tert-butyl-2-phenylphenol and 2,3-dimethyl-1,4,4a,9a-tetrahydro-9,10-nonanedione, which had a high content in this research, were undetected in teak from Indonesia and Panama. Although ketones appeared less than in other literature, 2,3-dimethyl-1,4,4a,9a-tetrahydro-9,10-nonanedione was similar to lappaol, deoxylapram and its isomers in structure. Extractives of the teak grown in the B region of Panama, increased in the amount from the sapwood to heartwood, which was consistent with the results obtained in this paper that the heartwood extractives were greater than the sapwood [30,31]. It should be noted that some compounds might not belong to wood extractives, such as estriol, a mammalian hormone, and antioxidant of butyl(2-chlorocyclohexyl) methyl phthalate. These compounds might be the dissolved impurity from the plastic lips. 


\subsection{Discussion in the Chromatic Aberration Between Heartwood and Sapwood}

Although the proportion of extractives in wood is small, they play an important role in the particular characteristics such as the color and smell of the wood, which is highly related to wood discoloration [32,33]. The extractives contained chromatic substances such as pigments, tannins and resins. Most of these color-related components had phenolic hydroxyl groups, carbonyl groups, double bond structures, etc. [34]. In the acetone extractives of heartwood (Figure 3), the substances with these structures, such as olefins and phenols, were more than those in the sapwood, which may be one of the reasons why the color of heartwood was darker than the sapwood. From the differences in compositions, it can be assumed that phenols, quinones, and ketones in teak may be the main extractives that caused heartwood to be darker than sapwood. Also, the substances with significant differences in the content of heartwood and sapwood (Table 6) have the chemical groups related to wood color such as phenolic hydroxyl group, carbonyl group and double bond, which might be the main composition for the chromatic aberration of teak.

The increase of chromophoric group and auxochrome group in the extractives after illumination caused a change in wood color [3]. The yellowness of the surface may be related to the amount of the 2-methylindole [35]. But due to the small amounts of extractives, the different extractive effects under different solvents which may change the compositions in the same wood and the relationship between tree-age and extractives, the relationship between extractives and discoloration, and the mechanism of discoloration of teak, have not been well explained. Therefore, further study will focus on the mechanism of discoloration of teak.

\section{Conclusions}

The difference in content of the main components between heartwood and sapwood was slight. They both were appeared to be weakly acidic. The moisture of heartwood was slightly lower than that of sapwood. The content in alcohol-benzene and acetone were obviously different between heartwood and sapwood.

The acetone extractives in heartwood were higher in composition and content than those in sapwood; 49 components were detected in the acetone extractive of the heartwood, and 26 components were detected in the sapwood. The high content in the teak heartwood was mostly detected in the sapwood.

In the acetone extractives, the substances of phenols, quinones and ketones in sapwood were obviously less than those in the heartwood. These substances may be the main components that made the heartwood darker than the sapwood.

The most obvious distinct substances in acetone extractives between heartwood and sapwood were 4-tert-butyl-2-phenyl-phenol, 2-methyl-anthraquinone and 2,3-dimethyl-1,4,4a, 9a-tetrahydro-9, 10 -anthracenedione\#.

This paper on the issue was a preliminary study. Since GC-MS was not the most accurate analysis method, a liquid chromatography system like high-performance liquid chromatography (HPLC) with UV-MS will be used to confirm the possible substance for the chromatic aberration in teak from China in a further study.

Author Contributions: H.Q. performed the experiments, analyzed the data, and wrote the manuscript; R.L. revised the manuscript; L.L. conceived and designed the experiments.

Funding: This study was financially supported by the National Key Research and Development Program of China (No. 2016YFD0600704).

Conflicts of Interest: The authors declare no conflict of interest. 


\section{References}

1. Tanaka, N.; Hamazaki, T.; Vacharangkura, T. Distribution, growth and site requirements of teak [Tectona grandis]. Jpn. Agric. Res. Q. 1998, 32, 65-77.

2. Francis, J.K.; Vozzo, J.A. Tectona grandis L.f. In Tropical Tree Seed Manual; USDA Forest Service: Washington, DC, USA, 2002; pp. 745-746.

3. Lian, C.P.; Pan, B.; Wang, F.; Tang, J.; Yin, W.X. Research on Teak Light-induced Discoloration and Mechanism. For. Mach. Wood Eq. 2015, 43, 21-24.

4. Nair, K.R.; Mukerji, H.K. A statistical study of the variability of physical and mechanical properties of Tectona grandis (Teak) grown at different localities of India and Burma and the effects of the variability on the choice of the sampling plan. Indian For. Rec. 1960, 1, 49.

5. Ponneth, D.; Vasu, A.E.; Easwaran, J.C.; Mohandass, A.; Chauhan, S.S. Destructive and non-destructive evaluation of seven hardwoods and analysis of data correlation. Holzforschung 2014, 68, 951-956. [CrossRef]

6. Seviset, S.; Piromgran, T.; Saributr, U.; Porncharoen, R.; Raerai, K.; Charoensettasilp, S. Mechanical Property of 9 Years Old Thinning of Teak Plantation in Thailand. MATEC Web Conf. 2017, 95, 03004. [CrossRef]

7. Rizanti, D.E.; Darmawan, W.; George, B.; Merlin, A.; Dumarcay, S.; Chapuis, H.; Gérardin, C.; Gelhaye, E.; Raharivelomanana, P.; Sari, R.K. Comparison of teak wood properties according to forest management: Short versus long rotation. Ann. For. Sci. 2018, 75, 39. [CrossRef]

8. Huang, G.; Liang, K.; Zhou, Z.; Yang, G.; Muralidharan, E.M. Variation in Photosynthetic Traits and Correlation with Growth in Teak (Tectona grandis Linn.) Clones. Forests 2019, 10, 44. [CrossRef]

9. Guzmán, N.; Moya, R.; Murillo, O. Evaluation of Bent Trees in Juvenile Teak (Tectona grandis L.f.) Plantations in Costa Rica: Effects on Tree Morphology and Wood Properties. Forests 2017, 8, 79. [CrossRef]

10. Zhou, Z.Z.; Liu, S.C.; Liang, K.N.; Ma, H.M.; Huang, G.H. Growth and mineral nutrient analysis of teak (Tectona grandis) grown on acidic soils in south China. J. Forest. Res. 2017, 28, 503-511. [CrossRef]

11. Yin, X.; Huang, A.; Zhang, S.; Liu, R.; Ma, F. Identification of Three Dalbergia Species Based on Differences in Extractive Components. Molecules 2018, 23, 2163. [CrossRef]

12. Gardini, C.; Urso, E.; Guerrini, M.; Van Herpen, R.; De Wit, P.; Naggi, A. Characterization of Danaparoid Complex Extractive Drug by an Orthogonal Analytical Approach. Molecules 2017, 22, 1116. [CrossRef]

13. Musumeci, L.E.; Ryona, I.; Pan, B.S.; Loscos, N.; Feng, H.; Cleary, M.T.; Sacks, G.L. Quantification of Polyfunctional Thiols in Wine by HS-SPME-GC-MS Following Extractive Alkylation. Molecules 2015, 20, 12280-12299. [CrossRef]

14. Belt, T.; Hänninen, T.; Rautkari, L. Antioxidant activity of Scots pine heartwood and knot extractives and implications for resistance to brown rot. Holzforschung 2017, 71, 527-534. [CrossRef]

15. Kallbom, S.; Moghaddam, M.; Walinder, M. Liquid sorption, swelling and surface energy properties of unmodified and thermally modified Scots pine heartwood after extraction. Holzforschung 2018, 72, 251-258. [CrossRef]

16. Laskowska, A.; Sobczak, J.W. Surface chemical composition and roughness as factors affecting the wettability of thermo-mechanically modified oak (Quercus robur L.). Holzforschung 2018, 72, 993-1000. [CrossRef]

17. Hisamochi, R.; Watanabe, Y.; Sano, M.; Nakatsuka, T.; Kurita, N.; Matsuo-Ueda, M.; Yamamoto, H.; Tazuru, S.; Sugiyama, J.; Subiyanto, B. Cellulose oxygen isotopic composition of teak (Tectona grandis) collected from Java Island: A tool for dendrochronological and dendroclimatological analysis. Dendrochronologia 2018, 52, 80-86. [CrossRef]

18. Brocco, V.F.; Paes, J.B.; Costa, L.G.A.D.; Brazolin, S.; Arantes, M.D.C. Potential of teak heartwood extracts as a natural wood preservative. J. Clean. Prod. 2017, 142, 2039-2099. [CrossRef]

19. Leonardo, F.V.S.; Rocha, H.F.; Mendoza, Z.M.S.H. Chemical compounds in teak. Pesqui. Florest. Bras. 2015, 35, 315-322.

20. Lukmandaru, G.; Ashitani, T. Color and chemical characterization of partially black-streaked heartwood in teak (Tectona grandis). J. Forest. Res. 2009, 20, 377. [CrossRef]

21. Nakano, J.; Takama, H.; Masano, J.; Ishizu, A. Wood Chemistry; Bao, H.; Li, Z.Z., Translators; China Forestry Publishing House: Beijing, China, 1989.

22. Shi, S.; He, F. Analysis and Detection of Pulp and Paper Making; China Light Industry Press: Beijing, China, 2009.

23. Vieitez, I.; Maceiras, L.; Jachmanián, I.; Alborés, S. Antioxidant and antibacterial activity of different extracts from herbs obtained by maceration or supercritical technology. J. Supercrit. Fluids 2018, 133, 58-64. [CrossRef] 
24. Walker, J.C.F. Primary Wood Processing: Principles and Practice; Chapman \& Hall: London, UK, 1993.

25. Standard Test Method for Preparation of Extractive-Free Wood; ASTM International: West Conshohocken, PA, USA, 2001.

26. Ono, K.; Hiraide, M.; Amari, M. Determination of lignin, holocellulose, and organic solvent extractives in fresh leaf, litterfall, and organic material on forest floor using near-infrared reflectance spectroscopy. J. Forest. Res. 2003, 8, 191-198. [CrossRef]

27. Chen, F.S.; Yuan, S.S. Research progress on the removal of acetone extract from plant raw materials. Hunan Papermak. 2015, 2, 29-31.

28. Liu, Y.X.; Zhao, G.J. Wood Science; China Forestry Publishing House: Beijing, China, 2012.

29. Deng, Z. Development of an alternative solvent to replace benzene in the determination of organic soluble extractives in wood. World Pulp Pap. 2006, 25, 32-34.

30. Lukmandaru, G.; Takahashi, K. Radial distribution of quinones in plantation teak (Tectona grandis L.f.). Ann. For. Sci. 2009, 66, 605. [CrossRef]

31. Windeisen, E.; Klassen, A.; Wegener, G. On the chemical characterisation of plantation teakwood from Panama. Holz als Roh- und Werkstoff 2003, 61, 416-418. [CrossRef]

32. Tolvaj, L.; Faix, O. Artificial Ageing of Wood Monitored by DRIFT Spectroscopy and CIE L*a*b* Color Measurements. 1. Effect of UV Light. Holzforschung 1995, 49, 397-404. [CrossRef]

33. Sehlstedt-persson, M. Colour responses to heat-treatment of extractives and sap from pine and spruce. In Proceedings of the 8th International IUFRO Wood Drying Conference, Brasov, Romania, 24-29 August 2003; pp. 459-464.

34. Johansson, C.I.; Saddler, J.N.; Beatson, R.P. Characterization of the polyphenolics related to the colour of western red cedar (Thuja plicata Donn) heartwood. Holzforschung 2000, 54, 246-254. [CrossRef]

35. Li, H.; Zeng, D.; Huang, Z.Z. Analysis of extractive compounds in teakwood before and after irradiation by chromatography-mass spectrometry. J. Central South. Univ. Forest. Technol. 2018, 38, 122-128.

(C) 2019 by the authors. Licensee MDPI, Basel, Switzerland. This article is an open access article distributed under the terms and conditions of the Creative Commons Attribution (CC BY) license (http://creativecommons.org/licenses/by/4.0/). 